Research Article

\title{
Long-Term Skid Resistance Evaluation of GAC-16 Based on Accelerated Pavement Testing
}

\author{
Xinquan $X u \mathbb{D}^{1,2}$ Yunhong $Y u^{1}{ }^{1}$ Jun Yang $\mathbb{D}^{1}$, and Chuanhai $W u^{2}$ \\ ${ }^{1}$ School of Transportation, Southeast University, No. 2 Sipailou, Nanjing 210096, China \\ ${ }^{2}$ Guangdong Hualu Transport Technology Co, Ltd., No. 1180 Guangcong Eighth Road, Guangzhou 510435, China
}

Correspondence should be addressed to Jun Yang; yangjun@seu.edu.cn

Received 4 February 2020; Revised 2 April 2020; Accepted 5 May 2020; Published 26 May 2020

Academic Editor: Tomasz Trzepieciński

Copyright (c) 2020 Xinquan Xu et al. This is an open access article distributed under the Creative Commons Attribution License, which permits unrestricted use, distribution, and reproduction in any medium, provided the original work is properly cited.

In this paper, four antiskidding surface test sections were paved to investigate the long-term skid resistance of the improved densegraded asphalt concrete in Guangdong Province (GAC) using diabase fine aggregate instead of limestone. Four test sections were tested by the accelerated loading equipment (MLS11, mobile load simulator). The reduction law of the long-term skid resistance of GAC-16 was analyzed based on the accelerated pavement testing results. Prediction models of the GAC-16 skid resistance were also established and verified. The evaluation indexes of the long-term skid resistance of the asphalt pavement were introduced, and the antiskidding durability of different sections was evaluated. Results show that the initial British pendulum number (BPN) and mean texture depth (MTD) of the asphalt pavement cannot completely characterize its long-term skid resistance. With increasing loading cycles, the attenuation law of the BPN and MTD of GAC-16 denotes a fast reduction during the early stage, which gradually stabilizes. The relation between the skid resistance index and accelerated loading cycles was analyzed by nonlinear fitting according to the least-squares-method principle. The attenuation law of the BPN and MTD of GAC-16 with loading cycles was in accordance with the exponential and logarithmic models, respectively. The long-term antiskidding performance of the asphalt pavement could be accurately characterized using a stable BPN, loading cycles while reaching a stable BPN, the initial MTD value, and the MTD reduction rate as the evaluation indexes of the skid resistance of asphalt pavement. Compared with limestone fine aggregate, diabase fine aggregate can improve the long-term skid resistance of the asphalt mixtures.

\section{Introduction}

Majority of the road traffic accidents can be attributed to the lack of skid resistance of pavement. The maintenance of road antiskidding performance ensures safe and fast driving [1,2]. However, the issue of the rapid decline in the skid resistance of the highway asphalt pavement has become increasingly prominent with the rapid growth of traffic volume [3, 4]. A previously conducted study has reported that the initial skid resistance of a dense-graded asphalt pavement is high, whereas its sideway force coefficient, which is an index of the skid resistance performance, rapidly decays within one or two years after opening to traffic and gradually declines until a relatively stable level [5]. Methods to postpone the decline in the antiskidding performance of the asphalt pavement and improve the long-term skid resistance of the asphalt pavement have been popular research subjects worldwide. Theoretical simulation, indoor tests, accelerated pavement test, and surveys on test roads are some main methods that are currently used for evaluating the antiskidding performance of the asphalt pavements. Yang et al. [6] performed a numerical simulation to establish a high-speed driving model for vehicles on wet roads and analyzed the skid resistance of the asphalt pavement under the combined effects of vehicles and water film. In addition, scholars [7-10] have characterized the effects of the asphalt mixture type, grading, asphalt content, and aggregate mechanical index (crushing value, Los Angeles wear loss, and polishing value) on the antiskidding performance of the asphalt mixture, and the attenuation model was established through laboratory tests. However, there is a major difference between the indoor rutting test slab and the actual asphalt pavement surface [11]. 
Accurate characterization of the asphalt pavement performance based on the antiskidding performance of the indoor rutting test slab is difficult. The decline in the skid resistance of the asphalt pavement tends to last for a long period, and accurate simulation of the actual driving conditions is difficult. Hence, only a few studies have been conducted to investigate the long-term antiskidding durability of the asphalt pavement. Further, the accelerated pavement testing is an effective methodology for evaluating the pavement performance at present. It can simulate practical traffic situations on site. The accelerated pavement test can be performed on a full-scale pavement in a short period of time using a controlled axle load for a long time to simulate the damages caused to the pavement because of the actual traffic load in a longer period. Thus, the long-term performance of the structure or materials of a pavement can be accurately evaluated, and the effectiveness of the pavement performance model can be validated [12-14].

In this study, four sections were paved in Renxin expressway in Guangdong Province, China. The field accelerated pavement testing was performed on the test sections, and the attenuation law of the skid resistance indexes such as the mean texture depth (MTD) and the British pendulum number (BPN) in different sections was analyzed. The applicability of the antiskidding performance prediction models of the asphalt pavement was verified by the longterm skid resistance of different sections. And new evaluation index to characterize the long-term skid resistance of the asphalt pavement was introduced. The research results can be applied to optimize the antiskidding surface materials and provide a basis for road maintenance.

\section{Test Program}

2.1. Test Road Section. Guangdong is a hot and rainy region located in Southern China. The road traffic volume is large, resulting in high requirements from the antiskidding performance of the pavement. However, there is a deficiency of high-quality materials for road construction in Guangdong. Majority of the coarse aggregates used in the surface layer comprise diabase, diorite, or andesite, whereas fine aggregates generally comprise machine-made sand processed from limestone. In this project, an improved dense-graded asphalt mixture with nominal maximum particle size of $16 \mathrm{~cm}$ in Guangdong Province (GAC-16) was selected as the research object. Four antiskidding surfaces were designed by considering the lithology, grading, and other factors of the coarse and fine aggregates. The antiskidding surface sections are shown in Table 1. The base layer and the middle and lower layers in the four sections were identical. Figure 1 depicts the pavement structure of the test section. The differences reflected that the coarse aggregate of the S1 antiskidding surface layer comprised diabase from Rucheng in Hunan Province. The coarse aggregate of the antiskidding surface in S2 and S4 comprised diabase from Heyuan in Guangdong Province, whereas the machine-made sand from limestone is the fine aggregate. Both the coarse and fine aggregates of the antiskidding surface in S3 are diabase from Heyuan in Guangdong Province. The paving works in all the sections were performed by the same construction technology.

Tables 2 and 3 present the technical indicator results of the coarse and fine aggregates used herein, respectively. The filler was the mineral powder obtained from grinded limestone, whereas the binder was Shell SBS (I-D)-modified asphalt (PG76-22). The technical indicator test results of the raw material satisfied the requirements of the current Chinese technical specifications for highway asphalt pavements [15].

Figure 2 presents the synthetic grades designed according to the aggregate screening results in which the gradation in S2 was observed to be relatively fine; the gradations in S3 and S4 were basically the same, whereas that in S1 was the thickest. The optimal asphalt content of four gradations was determined by the Marshall mix design method (the test specimen was subject to compaction by means of 75 blows per each face). The best asphalt content in S1 was $4.7 \%$, and the optimal asphalt content in S2, S3, and S4 was $4.6 \%$. Marshall specimens were formed under the optimal asphalt content conditions, and the technical specifications of the asphalt mixture were determined. The results are shown in Table 4. From Table 4, it can be seen that the volume index, high temperature stability, and water stability of the four asphalt mixtures are not significantly different, and they all satisfied the requirements of China's asphalt pavement technology specification [15].

2.2. Methodology. The accelerated loading test was performed using PaveMLS 11 (Figure 3(a)) manufactured by PAVETING (UK). The device has an effective loading length of $1.1 \mathrm{~m}$, a loading width of $80 \sim 230 \mathrm{~mm}$, and a maximum loading speed of 7200 times/h.

The test was conducted from October 2, 2018, to November 7, 2018, to evaluate the skid resistance of the pavement. The loading test periods in Guangdong were during the autumn. The test temperature under natural conditions ranged from $15^{\circ} \mathrm{C}$ to $30^{\circ} \mathrm{C}$. Each test section was loaded according to the scheme presented in Table 5. A preloading of 2000 cycles was performed before the formal loading to compact the road surface.

The mean texture depth (MTD) and British pendulum number (BPN) of the loading belt were tested by the sand patch test and BPN test after each loading (Figures $3(\mathrm{~b})$ and $3(c))$. Both the MTD and BPN were tested according to the method specified in JTGE60-2008 of China's Highway Subgrade and Pavement Field Test Regulations. Further, temperature correction was conducted according to the regulations. Each loading zone was tested at four points. The average was considered to be the test result.

\section{Test Results and Discussion}

3.1. BPN Test Results. The BPN of the road reflects the surface microstructure. The richer the road surface microstructures, the greater the BPN and the better the skid resistance of the asphalt pavement [16]. With respect to the four sections, the initial BPN and that after 1.02 million 
TABLE 1: Antiskidding surface layer scheme.

\begin{tabular}{lcccc}
\hline No. & Binder grade & Mix type & Coarse aggregate & Fine aggregate \\
S1 & $76-22$ & GAC-16 & Diabase 1 & Limestone \\
S2 & $76-22$ & GAC-16 & Diabase 2 & Limestone \\
S3 & $76-22$ & GAC-16 & Diabase 2 & Diabase 2 \\
S4 & $76-22$ & GAC-16 & Diabase 2 & Limestone \\
\hline
\end{tabular}

Note. S1, S2, S3, and S4 are test sections 1, 2, 3, and 4, respectively. Diabase 1 is produced in Rucheng County, Hunan Province. Diabase 2 is produced in Heyuan city, Guangdong Province. Limestone is produced in Wengyuan County, Guangdong Province.

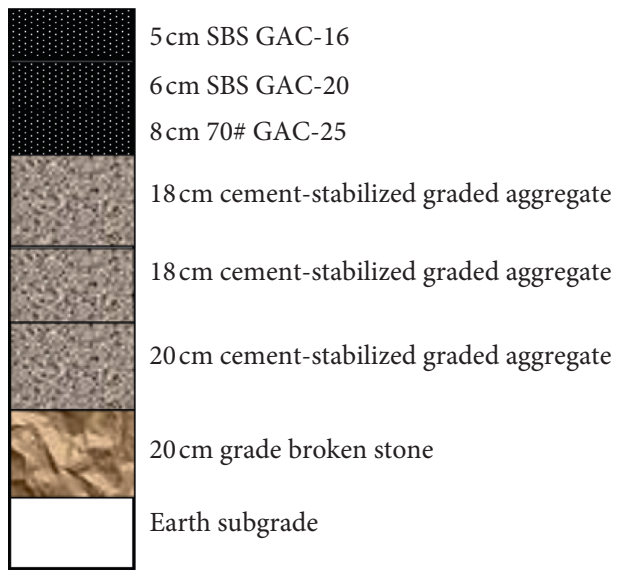

Figure 1: Pavement structure of the test section.

TABLE 2: Test results of the coarse aggregate technical indicators.

\begin{tabular}{lccc}
\hline Test index & \multirow{2}{*}{ Test method } & Technical requirements & \multicolumn{2}{c}{ Test results } & Diabase 1 & Diabase 2 \\
\hline Crushed stone value (\%) & T0316 & $\leq 20$ & 9.4 \\
Los Angeles wear loss (\%) & T0317 & $\leq 24$ & 10.6 \\
Polished stone value (BPN) & T0321 & $\geq 42$ & 46.0 \\
\hline
\end{tabular}

Note. Crushed stone value can characterize the ability of stone to resist crushing, and it is expressed as a percentage of the mass of stone smaller than the specified particle size after crushing test. The polished stone value can reflect the ability of coarse aggregate to resist the tire polishing.

TABle 3: Test results of the fine aggregate technical indicators.

\begin{tabular}{|c|c|c|c|c|}
\hline \multirow{2}{*}{ Test index } & \multirow{2}{*}{ Test method } & \multirow{2}{*}{ Technical requirements } & \multicolumn{2}{|c|}{ Test results } \\
\hline & & & Limestone & Diabase \\
\hline Sand equivalent (\%) & T0334 & $\geq 65$ & 68.0 & 72.0 \\
\hline Fine aggregate angularity value (s) & T0345 & $\geq 30$ & 35.3 & 43.1 \\
\hline
\end{tabular}

Note. Fine aggregate angularity value can reflect the shape and surface roughness of fine aggregate.

loading cycles were obtained and are presented in Table 6. Figure 4 depicts the attenuation trend of the BPN with the loading cycles.

Table 6 and Figure 4 present the following results:

(1) The initial BPN values in S1, S2, S3, and S4 were 77.4, $81.5,77.1$, and 84.9 , respectively. The initial BPN value was the largest in S4, followed by that in S2, S3, and S1. The initial BPN of the antislide surfaces of the asphalt pavement was mainly affected by the geometric shape, polishing value, and other physical and mechanical properties of the stones. In addition to the stone properties, the initial values were also related with the paving process, asphalt content, gradation, and nominal maximum aggregate size (NMAS). Generally, the higher the mass content of the coarse aggregate and the greater the NMAS, the easier it is to obtain a higher initial BPN value [17]. Further, the larger the asphalt content is, the smaller will be the BPN of the mixture. Excessive compaction may result in the abrasion of the surface aggregate, leading to a decrease in the BPN of the pavement [18]. The gradation curves in S1, S3, and S4 were basically the same, whereas the passing rate of the 


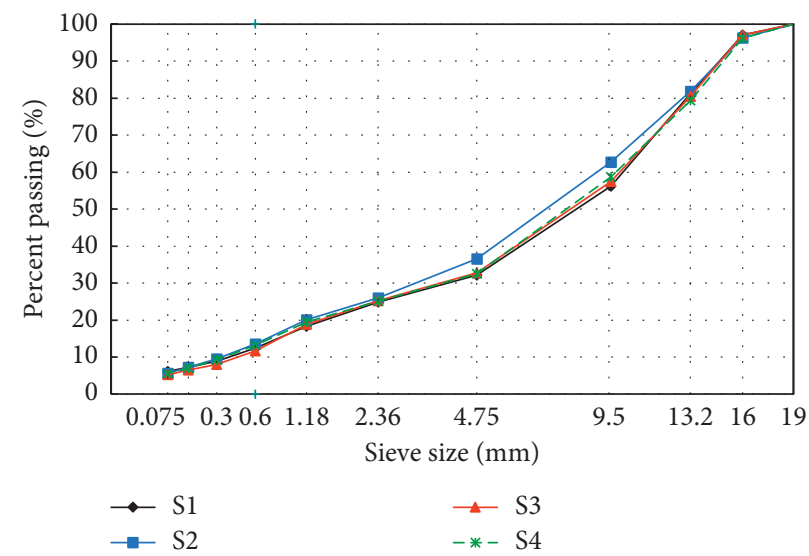

FIGURE 2: Design gradation curve.

TABLE 4: Technical specifications of the asphalt mixture.

\begin{tabular}{|c|c|c|c|c|c|c|}
\hline Program & Test method & Technical requirements & S1 & S2 & S3 & S4 \\
\hline Asphalt content (\%) & - & - & 4.7 & 4.6 & 4.6 & 4.6 \\
\hline Volume of air voids (\%) & - & $4 \sim 6$ & 4.3 & 4.0 & 4.4 & 4.1 \\
\hline Void filled with asphalt (\%) & - & $65 \sim 75$ & 69.3 & 70.8 & 68.1 & 69.7 \\
\hline Void in mineral aggregate $(\%)$ & - & $\geq 13.5$ & 13.7 & 13.8 & 13.9 & 13.9 \\
\hline Marshall stability $(\mathrm{kN})$ & T0709 & $\geq 8.0$ & 15.61 & 14.23 & 14.65 & 14.21 \\
\hline Flow value $(0.1 \mathrm{~mm})$ & T0709 & $15 \sim 40$ & 35.1 & 27.6 & 28.8 & 30.4 \\
\hline Residual stability (\%) & T0709 & $\geq 80$ & 97.4 & 94.6 & 90.3 & 93.6 \\
\hline Tensile strength ratio of freeze-thaw splitting (\%) & T0729 & $\geq 75$ & 95.3 & 89.6 & 92.5 & 88.5 \\
\hline
\end{tabular}

Note. Residual stability is the ratio of Marshall stability of water intrusion to standard Marshall stability; tensile strength ratio of freeze-thaw splitting is the ratio of the splitting strength of Marshall specimens subjected to freeze-thaw cycles to that of standard Marshall specimens.

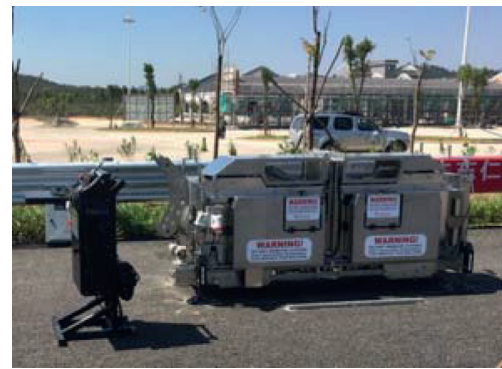

(a)

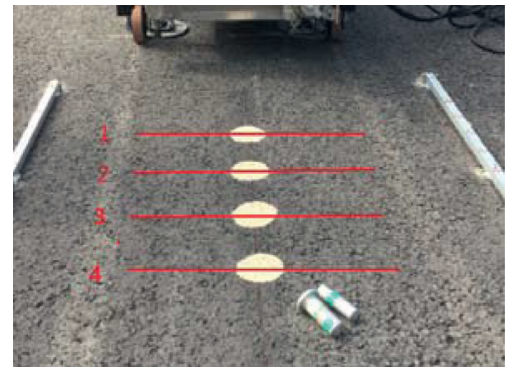

(b)

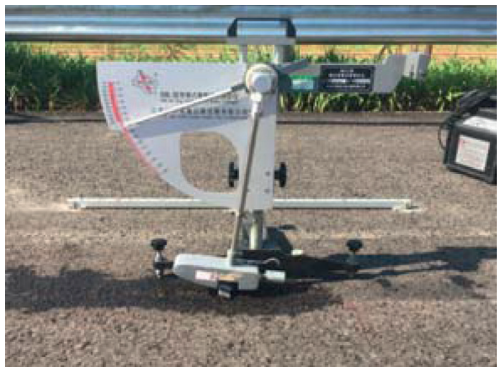

(c)

Figure 3: Loading equipment and test method. (a) PaveMLS 11. (b) Sand patch test. (c) BPN test.

TABLE 5: Accelerated loading test plan.

\begin{tabular}{lccccc}
\hline $\begin{array}{l}\text { Load cycles } \\
(10000 \text { cycles })\end{array}$ & $\begin{array}{c}\text { Loading } \\
\text { position }\end{array}$ & Test index & $\begin{array}{c}\text { Loading speed } \\
(\mathrm{km} / \mathrm{h})\end{array}$ & $\begin{array}{c}\text { Tire pressure } \\
(\mathrm{MPa})\end{array}$ & $\begin{array}{c}\text { Environmental } \\
\text { conditions }\end{array}$ \\
\hline 100 & $\begin{array}{c}\text { Hard } \\
\text { shoulder }\end{array}$ & $\begin{array}{c}\text { MTD, BPN, apparent } \\
\text { condition }\end{array}$ & 50 & 0.7 & $\begin{array}{c}\text { Natural environment air temperature: } \\
15-30^{\circ} \mathrm{C}\end{array}$ \\
\hline
\end{tabular}

gradation curve in S2 at $9.5 \mathrm{~mm}$ and $4.75 \mathrm{~mm}$ sieve holes are higher than the other three mixtures. The same rolling technology was adopted for construction in the four sections; hence, the difference in BPN can be considered to be independent of the rolling technology. The types of coarse and fine aggregates employed in S2 and S4 were similar; however, the gradation in S4 was lower than that in S2, and the initial BPN in S4 was larger than that in S2, which conformed to the rule that the higher the content of the coarse aggregate is, the larger will be the BPN. The gradation curve in S1, S3, and S4 was basically 
TABLE 6: BPN and loading cycles.

\begin{tabular}{lcccc}
\hline Test sections & S1 & S2 & S3 & S4 \\
\hline BPN before loading & 77.4 & 81.5 & 77.1 & 84.9 \\
BPN after loading 1.02 million cycles & 64.3 & 61.9 & 64.4 & 62.5 \\
BPN attenuation value & 13.1 & 19.6 & 12.7 & 22.4 \\
BPN decay rate (\%) & 16.9 & 24.0 & 16.5 & 26.4 \\
\hline
\end{tabular}

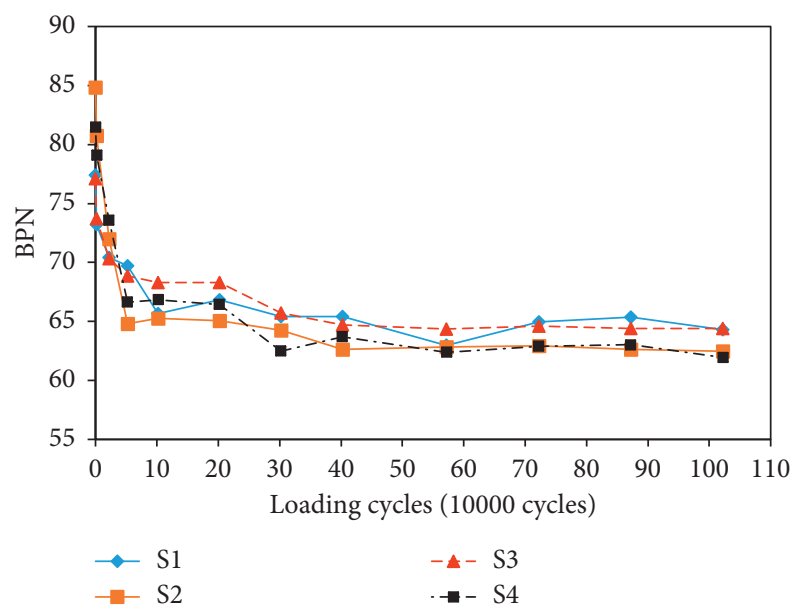

Figure 4: BPN test results.

the same; nevertheless, the initial BPNs in S1 and S3 were significantly lower than those in S4. When compared with S4, S3 used the diabase fine aggregate instead of the limestone fine aggregate, whereas S1 used the diabase coarse aggregate with smaller crushing and wear values when compared with those of S4. Furthermore, the asphalt content in S1 was $0.1 \%$ larger than that in S4, and the oil film thicknesses in S1, S3, and S4 were 8.12, 8.15, and $7.95 \mu \mathrm{m}$, respectively. The initial BPNs in S1 and S3, which were lower than those in S4, were related to the relatively large thickness of the asphalt film. The microtexture of the aggregate in S1 and S3 was wrapped by the asphalt film, leading to a smaller initial BPN compared to S4.

(2) The BPN of the four antislide surfaces gradually decreased as the loading cycles increased. The BPN maintained a rapid decline until 50,000 loading cycles mainly because the sharp projections and bulges on the road surface were quickly worn by the loading wheels during the initial stage of loading, leading to the fast attenuation of the BPN. The BPNs of the four sections were stable after 300,000 times of loading mainly because the sharp projections and bulges on the surface of the pavement were basically worn after completing certain times of loading. At this time, the antislide performance of the road surface was mainly determined by the microtexture of the aggregate; further, the friction coefficient of the road surface was stable.
(3) The BPNs in S1, S2, S3, and S4 were 64.3, 61.9, 64.4, and 62.5 , respectively, after 1.02 million times of accelerated loading. The amplitudes of BPN attenuation were 13.1, 19.6, 12.7, and 22.4, respectively. The final values of the BPN attenuation in S1 and S3 as well as S2 and S4 were basically equal. With the wearing of vehicle tires, the peaks and the bulges of the road surface were gradually polished; therefore, the road surface BPN was mainly determined based on the polishing value of the aggregate. S2 and S4 considered the same aggregate, and only the gradation was different. Therefore, the BPN of the two tended to be the same with the effect of the wheel load. The mechanical indexes (i.e., polishing, crushing, and wear values) of the coarse aggregates played a decisive role in the antiskidding durability of asphalt pavements $[7,16]$. When compared with S4, the coarse aggregates employed in S1 were polished. The value was slightly larger than that in S3; the crushing and wear values were smaller than those in S3; and the stable BPN was larger than that in S4. When compared with S4, S3 had a stable BPN greater than that in S4, believed to be mainly caused by the usage of diabase fine aggregate in S3, and its wear resistance and angularity were better than those of the fine aggregate in S1 (limestone). The fine aggregate properties have an important influence on the antiskidding durability of the asphalt mixture.

3.2. MTD Test Results. MTD reflects the macroscopic texture of the pavement. The greater the value is, the greater will be the road surface roughness, facilitating drainage from the road surface and resulting in an improved safety driving condition [17-20]. The initial MTD values in the four sections and the MTD values after 1.02 million loading cycles are presented in Table 7. Figure 4 depicts the attenuation trend of the MTD with the loading cycles.

Figure 5 and Table 7 present the following results:

(1) The initial MTD in S1, S2, S3, and S4 was 1.09, 0.89, 0.98 , and $0.99 \mathrm{~mm}$, respectively. It is generally believed that the higher the coarse aggregate content and the larger the NMAS, the greater will be the MTD of the asphalt mixture $[16,19]$. The pass percentage of the $4.75 \mathrm{~mm}$ mesh in S1, S2, S3, and S4 was $32.2 \%, 36.6 \%, 32.8 \%$, and $32.5 \%$, respectively, whereas that of the $9.5 \mathrm{~mm}$ mesh was $56.2 \%, 62.7 \%$, $57.4 \%$, and $58.7 \%$, respectively. The gradations in S1, S3, and S4 were thicker than those in S2; therefore, the initial MTD value of S2 was considered to be the smallest. The gradation in S3 was basically the same as that in S4, and the initial MTD value was almost the same. The pass percentage of the $9.5 \mathrm{~mm}$ mesh in S1 was slightly lower; further, the coarse aggregate content was relatively higher, and the initial MTD value was the largest.

(2) The MTD of the four antislide surfaces gradually decreased as the loading cycles increased. The MTD 
TABLE 7: MTD and loading cycles.

\begin{tabular}{|c|c|c|c|c|}
\hline Test sections & S1 & $\mathrm{S} 2$ & S3 & S4 \\
\hline MTD (mm) before loading & 1.09 & 0.89 & 0.98 & 0.99 \\
\hline MTD (mm) after loading 1.02 million cycles & 0.93 & 0.72 & 0.78 & 0.70 \\
\hline MTD attenuation value $(\mathrm{mm})$ & 0.16 & 0.17 & 0.2 & 0.29 \\
\hline MTD attenuation rate $(\%)$ & 14.7 & 19.1 & 20.4 & 29.3 \\
\hline
\end{tabular}

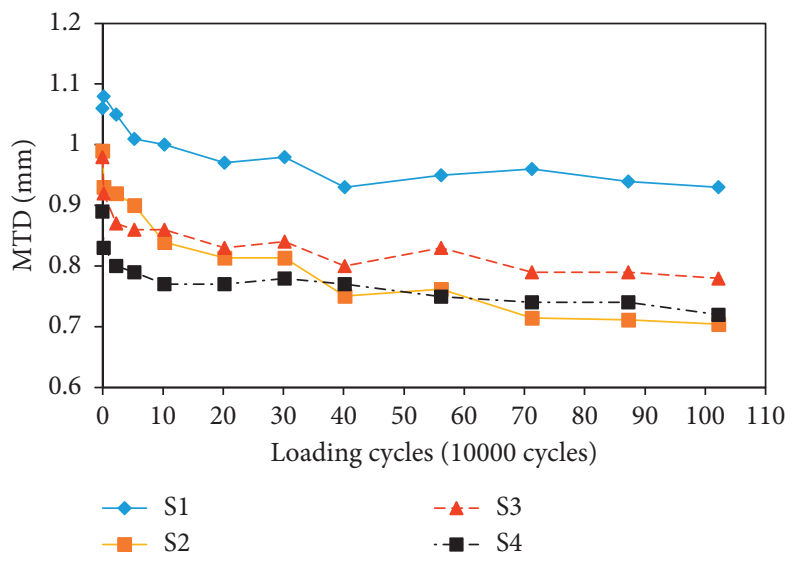

Figure 5: MTD test results.

in the four sections declined at a relatively high rate before 100,000 loading cycles. Further, the rate of the MTD attenuation became slower between 100,00 and 400,000 loading times mainly because the projections and the bulges on the road surface were worn off under the action of the loading tires, leading to MTD attenuation, during the early stage of loading.

(3) The MTDs of the four sections after 1.02 million loading cycles were $0.93,0.72,0.78$, and $0.70 \mathrm{~mm}$, respectively. The MTDs in S2 and S4 were basically the same, with that in S3 lying in the middle position and that in S1 being the largest. According to the attenuation rate of the MTD, S4 was the largest, followed by S3 and S2. S1 had the smallest attenuation rate mainly because the polishing value of the coarse aggregate adopted in S1 was relatively larger and the Los Angeles wear loss was relatively smaller. The coarse aggregate was relatively wear-resistant. The polishing value of the coarse aggregate and the Los Angeles wear loss under the same wheel load determined the attenuation rate of the pavement MTD. The higher the polishing value of the aggregate is, the smaller will be the Los Angeles wear loss and the slower will be the attenuation rate of the MTD of the antislide surface.

\section{Long-Term Skid Resistance Evaluation}

4.1. Verification of the Skid Resistance Prediction Model. Currently, scholars mainly adopt logarithmic and exponential models to predict the attenuation law of asphalt pavements [1, 4, 8]. Equations (1) and (2) present the exponential and logarithmic models used for predicting the degradation of skid resistance of the asphalt pavement, respectively.

$$
\begin{aligned}
& y=a_{0} \cdot e^{b_{0} \cdot n}+c, \\
& y=a_{1}-b_{1} \cdot \log (n),
\end{aligned}
$$

where $y$ is the antiskidding index (BPN, MTD) of the asphalt surface layer; $n$ is the number of the axle load times; and $a_{0}, b_{0}, c, a_{1}$, and $b_{1}$ are the model parameters.

The model parameters usually depend on the aggregate properties, gradation, oil stone ratio, traffic level, and environmental factors.

To verify the applicability of the model to the antiskid surface of GAC-16 pavement, ORIGIN2017 was used to analyze the relationship between the antiskid indexes (BPN, MTD) and the loading cycle using model (1) and model (2) for nonlinear fitting based on the least-squares-method principle. Tables 8 and 9 present the estimated parameters for BPN and MTD, respectively.

Tables 8 and 9 present the following observations: to perform BPN decay estimations, the average value of $R^{2}$ calculated by BPN attenuation prediction model is 0.935 in the exponential model and 0.914 in the logarithmic model, and the determination coefficient $R^{2}$ of the fitted curve obtained by adopting the exponential model is higher than that obtained by adopting the logarithmic model; in case of the MTD attenuation estimations, the average value of $R^{2}$ is 0.877 in exponential model, and the average value of $R^{2}$ is 0.885 in logarithmic model, and the determination coefficient $R^{2}$ of the fitted curve obtained by adopting the logarithmic model is higher than that obtained by exponential model. In other words, the BPN of the modified asphalt GAC-16 antislip surface layer attenuated with the loading cycles was in accordance with the exponential model (1), and the law of the MTD attenuated with the loading cycles was more in accordance with the logarithmic model (2).

4.2. Attenuation Evaluation of the BPN. Figure 6 depicts the reduction curves of attenuation on the pendulum friction coefficient for the four sections fitted using the exponential model (1). An observation of the fitted curves in Figure 6 depicts that the pendulum friction coefficient of the antislide surface in the four sections approached a stable value after applying for a certain number of loading cycle. The results showed that the pendulum friction coefficient of an antislide surface with a stable performance tended to become stable after being subjected to certain wheel loading cycles. The antislide surfaces comprising different materials exhibited different decay rates of the pendulum friction coefficient, 
TABLE 8: BPN attenuation prediction model parameters.

\begin{tabular}{|c|c|c|c|c|c|c|}
\hline \multirow{2}{*}{ Model } & \multirow[t]{2}{*}{ No } & \multicolumn{5}{|c|}{ Exponential model (1) } \\
\hline & & $a_{0}$ & $b_{0}$ & $c$ & $R^{2}$ & Fitted equation \\
\hline \multirow{4}{*}{ Exponential model (1) } & S1 & 10.33 & -0.218 & 65.0 & 0.906 & $y=10.33 \cdot e^{-0.218 \cdot n}+65.0$ \\
\hline & $\mathrm{S} 2$ & 20.24 & -0.480 & 63.6 & 0.984 & $y=20.24 \cdot e^{-0.480 \cdot n}+63.6$ \\
\hline & S3 & 9.69 & -0.141 & 65.1 & 0.887 & $y=9.69 \cdot e^{-0.141 \cdot n}+65.1$ \\
\hline & S4 & 17.06 & -0.283 & 63.7 & 0.953 & $y=17.06 \cdot e^{-0.283 \cdot n}+63.7$ \\
\hline \multirow{5}{*}{ Logarithmic model (2) } & No & $a_{1}$ & $b_{1}$ & $R^{2}$ & & Fitted equation \\
\hline & S1 & 70.97 & 3.486 & 0.887 & & $y=70.97-3.486 \cdot \log (n)$ \\
\hline & S2 & 73.61 & 6.355 & 0.882 & & $y=73.61-6.355 \cdot \log (n)$ \\
\hline & S3 & 71.45 & 3.642 & 0.955 & & $y=71.45-3.642 \cdot \log (n)$ \\
\hline & S4 & 73.87 & 6.324 & 0.933 & & $y=73.87-6.342 \cdot \log (n)$ \\
\hline
\end{tabular}

TABLE 9: MTD attenuation prediction model parameters.

\begin{tabular}{|c|c|c|c|c|c|c|}
\hline \multirow[t]{2}{*}{ Model } & \multirow[t]{2}{*}{ No } & \multicolumn{5}{|c|}{ Exponential model (1) } \\
\hline & & $a_{0}$ & $b_{0}$ & c & $R^{2}$ & Fitted equation \\
\hline \multirow{4}{*}{ Exponential model (1) } & $\mathrm{S} 1$ & 0.123 & -0.079 & 0.944 & 0.933 & $y=0.123 \cdot e^{-0.079 \cdot n}+0.944$ \\
\hline & S2 & 0.243 & -0.039 & 0.705 & 0.953 & $y=0.243 \cdot e^{-0.039 \cdot n}+0.705$ \\
\hline & S3 & 0.133 & -0.154 & 0.808 & 0.821 & $y=0.133 \cdot e^{-0.154 \cdot n}+0.808$ \\
\hline & S4 & 0.107 & -0.278 & 0.754 & 0.801 & $y=0.107 \cdot e^{-0.278 \cdot n}+0.754$ \\
\hline \multirow{5}{*}{ Logarithmic model (2) } & No & $a_{1}$ & $b_{1}$ & $R^{2}$ & & Fitted equation \\
\hline & S1 & 1.05 & 0.057 & 0.924 & & $y=1.05-0.057 \cdot \log (n)$ \\
\hline & $\mathrm{S} 2$ & 0.92 & 0.096 & 0.850 & & $y=0.92-0.096 \cdot \log (n)$ \\
\hline & S3 & 0.89 & 0.049 & 0.895 & & $y=0.89-0.049 \cdot \log (n)$ \\
\hline & S4 & 0.81 & 0.035 & 0.872 & & $y=0.81-0.035 \cdot \log (n)$ \\
\hline
\end{tabular}

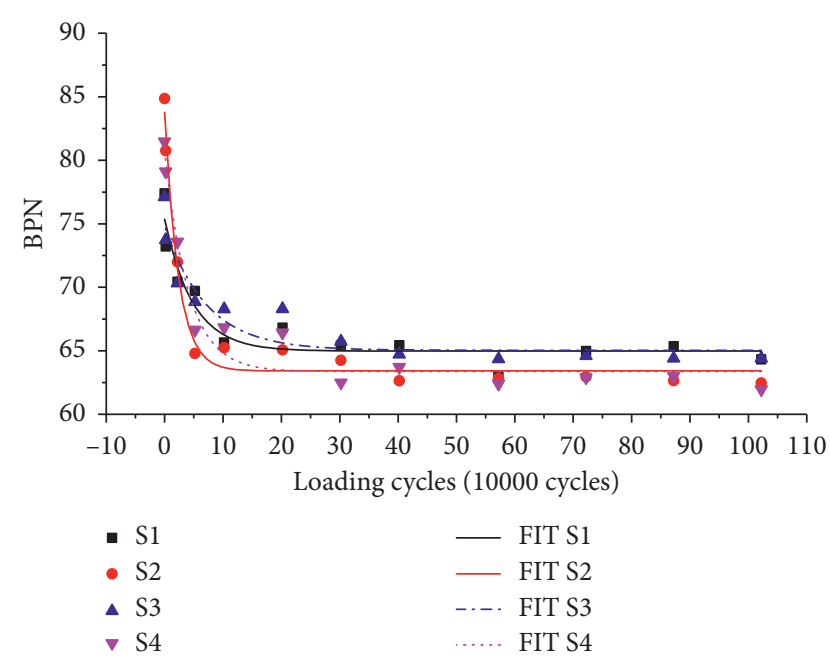

Figure 6: The BPN reduction fitting curve.

and the stable pendulum friction coefficients, which they tended to approach, and the loading cycles required for approaching such stable pendulum friction coefficients were different.

By analyzing model (1) for the attenuation estimations of the BPN for the GAC-16, we observed that the magnitude of the $a_{0}$ value in the model represented the attenuation amplitude of the BPN, $b_{0}$ represented the attenuation rate of the $\mathrm{BPN}$, and $c$ represented the stable value of the BPN attenuation. The larger the $a_{0}$ and $b_{0}$ values are, the faster will be the decay of the BPN; the larger the $c$ value is, the higher will be the BPN and the better will be the long-term antislide durability of the pavement. Therefore, the stable BPN and loading cycles that result in a stable BPN can be considered as the evaluation index of the antiskidding durability of the asphalt pavement.

For performing accurate comparisons and analysis, the times of accelerations required for approaching the stable BPN was defined as the number of times (10,000 times) when the value difference in the BPN and that of the stable BPN $c$ did not exceed 0.1 BPN. The difference value of $0.1 \mathrm{BPN}$ was selected mainly because the stable BPN accuracy of the measured pendulum friction coefficient was $0.1 \mathrm{BPN}$. The pendulum friction coefficient in the four sections after stability was reached, and the times of loading required for approaching the stable BPN are presented in Table 10 .

Table 10 presents that the stable pendulum friction coefficients in S1 and S3 were basically the same; however, the loading cycles in S3 required for approaching the stable pendulum friction coefficient were greater than those in S1. Therefore, from the point of view of the pendulum friction coefficient, which is an index for durability, S3 was better than S1. The stable pendulum friction coefficient in S2 and S4 was not much different but the loading cycles in S4 for reaching the stable pendulum friction coefficient were greater than those in S2; hence, S4 was better than S2. Further, the two indexes of the pendulum friction coefficient after comprehensive stabilization and the loading degree of the stable pendulum friction coefficient were evaluated. The long-term antiskidding performance of the four sections was ranked as $\mathrm{S} 3>\mathrm{S} 1>\mathrm{S} 4>\mathrm{S} 2$. 
TABLE 10: BPN evaluation indicators and calculation results.

\begin{tabular}{lcc}
\hline No. & Stable pendulum friction coefficient (BPN) & Loading cycles for stable BPN (10,000 cycles) \\
\hline S1 & 65.0 & 22 \\
S2 & 63.6 & 11 \\
S3 & 65.1 & 33 \\
S4 & 63.7 & 18 \\
\hline
\end{tabular}

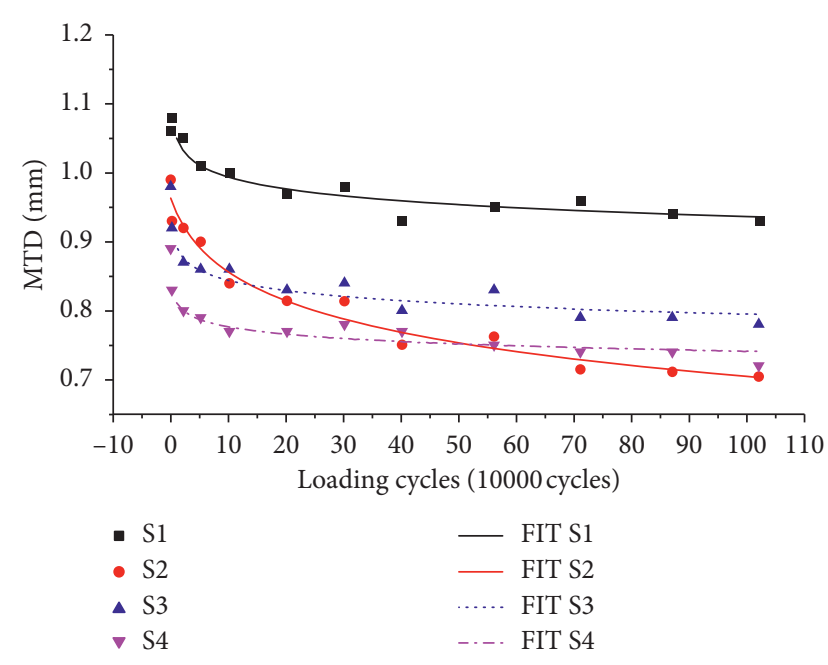

Figure 7: The MTD reduction fitting curve.

4.3. Attenuation Evaluation of the MTD. Figure 7 shows the reduction curves in the attenuation of the road surface MTD in the four sections obtained by fitting using the logarithmic model. An observation of the fitted curves in Figure 7 depicted that the curves for the attenuation trends of the MTD in S1, S3, and S4 were parallel with the increase in loading cycles. Meanwhile, the attenuation range of the MTD in S2 was relatively larger. This result may be related to the relatively high grading in S2 and its weak antiextrusion ability. Under the action of the tire load, the macroscopic texture of its road surface was worn and the aggregate was rearranged, leading to the faster attenuation rate of the MTD.

After analyzing the MTD attenuation prediction model, the $a_{1}$ value in the model was observed to characterize the initial value of the MTD and $b_{1}$ was observed to characterize the MTD attenuation rate. The larger the $a_{1}$ value is, the larger will be the initial construction depth; the larger the $b_{1}$ value is, the greater will be the MTD attenuation rate and the faster will be the decay of the MTD. Therefore, the initial $a_{1}$ value and the decay rate $b_{1}$ of the MTD can be selected as evaluation indexes of the antiskidding durability of the asphalt pavement. The larger the initial value $a_{1}$ of the MTD is, the smaller will be the attenuation rate $b_{1}$; the slower the attenuation of the MTD is, the better will be the drainage performance of the road surface and the long-term antiskidding performance of the asphalt mixture.

Table 7 presents that the initial MTD values in S1, S2, S3, and $\mathrm{S} 4$ were $1.09,0.89,0.98$, and $0.99 \mathrm{~mm}$, respectively, and that the decay rates were $0.147,0.191,0.204$, and 0.293 , separately. The calculation results of the initial MTD values and the attenuation rate indicated that the long-term antiskidding performance of the four antiskidding surface layers can be ranked as $\mathrm{S} 1>\mathrm{S} 3>\mathrm{S} 4>\mathrm{S} 2$.

The road surface texture is the decisive factor for ensuring the skid resistance of the road. Studies have denoted that the macro texture determines the maximum level of the antislide performance that can be obtained by a road surface through improvement. The macrotexture provides a drainage channel for the tire/road contact, which determines the attenuation amplitude of the antislide performance while the tire is performing a sliding movement [1, 2]. MTD mainly reflects the macrotexture of the road surface. The greater the value is, the bigger will be the drainage capacity of the road surface and the better will be the skid resistance of the road surface under wet conditions. BPN, which comprehensively reflects the macro- and microtextures of the road surface, is a direct index for evaluating the friction coefficient of the road surface. Therefore, according to the durability evaluation results of the BPN and MTD of the pavement, the following order of long-term skid resistance of the four sections can be obtained: S1 > S3 $>$ S4 $>$ S2.

\section{Conclusion}

In this paper, the effects of diabase fine aggregate replacing limestone fine aggregate on the long-term skid resistance of GAC-16 were investigated by field accelerated pavement testing, and the long-term skid resistance of four sections was evaluated. The following conclusions could be drawn:

(1) Mechanical indexes of the coarse and fine aggregate properties considerably influenced the antiskidding durability of the asphalt pavement. The usage of wear-resistant diabase fine aggregate instead of limestone fine aggregate can improve the long-term antiskidding performance of the asphalt mixtures.

(2) The on-site accelerated pavement testing verified that the attenuation law of the antiskidding index of BPN of the GAC-16 was in accordance with the exponential model and that the attenuation law of MTD was in accordance with the logarithmic model.

(3) The stabilized BPN, accelerated loading cycles at which the BPN became stable, initial MTD value, and MTD decay rate were used as the evaluation indexes of the long-term skid resistance of the asphalt pavement, which can accurately characterize the antiskidding durability of the asphalt pavement.

\section{Data Availability}

The experimental data used to support the findings of this study are included within the article. 


\section{Conflicts of Interest}

The authors declare that there are no conflicts of interest regarding the publication of this paper.

\section{Acknowledgments}

The authors sincerely acknowledge the funding support from the National Natural Science Foundation of China (grant no. 51778140) and the Guangdong Provincial Department of Transportation (grant no. 2016-02-013).

\section{References}

[1] X.-M. Huang and B.-S. Zheng, "Research status and progress for skid resistance performance of asphalt pavements," China Journal of Highway and Transport, vol. 32, no. 4, pp. 32-49, 2019, in Chinese.

[2] B. Mataei, H. Zakeri, M. Zahedi, and F. M. Nejad, "Pavement friction and skid resistance measurement methods: a literature review," Open Journal of Civil Engineering, vol. 6, no. 4, pp. 537-565, 2016.

[3] H.-L. Sun, "Study on attenuation characteristics of asphalt pavement skid resistance," Highway, vol. 7, pp. 73-78, 2011, in Chinese.

[4] Y. Huang, L. Shao, and C. Liu, "Experimental study on skidresistance of asphalt pavement," Journal of Highway and Transportation Research and Development, vol. 19, pp. 5-8, 2002.

[5] X. Xu, Study on the Impact of Asphalt Pavement Skid Resistance Performance to Traffic Safety, Beijing Architecture University, Beijing, China, 2013.

[6] J. Yang, H. Wang, and Q. Wu, "Numerical simulation on skid resistance property of wet asphalt pavement," Journal of Chang'an University: Natural Science Edition, vol. 36, pp. 25-32, 2016, in Chinese.

[7] T. Tianchi, A. Kumar, K. Cor, K. Reginald, S. Athanasios, and M. Eyad, "Finite element studies of skid resistance under hot weather condition," Transportation Research Record: Journal of the Transportation Research Board, vol. 2672, no. 40, pp. 382-394, 2018.

[8] L. Kong, G. Ying, W. Lin et al., "Anti-sliding performance attenuation model of asphalt pavement based on aggregate mechanical index," Journal of Changsha University of Science and Technology: Natural Science Edition, vol. 14, pp. 13-20, 2017, in Chinese.

[9] L. Cong and T.-J. Wang, "Effect of fine aggregate angularity on skid-resistance of asphalt pavement using accelerated pavement testing," Construction and Building Materials, vol. 168, pp. 41-46, 2018.

[10] R. Arash and M. Eyad, "Experimental-based model for predicting the skid resistance of asphalt pavements," International Journal of Pavement Engineering, vol. 14, no. 1, pp. 24-35, 2013.

[11] S. Zhang, Research on Multi-Scale Asphalt Pavement Skid Resistance Based on Inkrface Contact Performance, South China University of Technology, Guangzhou, China, 2015.

[12] P.-J. ZhangT. Cui et al., "Study on skid resistance of pavement with different gradation based on accelerated loading test," Journal of China \& Foreign Highway, vol. 36, no. 2, pp. 58-61, 2016.

[13] C. Ming and W. Shuo, "Accelerated pavement testing in Chinese mainland," in Proceedings of the 13th COTA
International Conference of Transportation Professionals (CICTP 2013), Shenzhen, China, August 2013.

[14] A. Haleh, M. Alaeddin, and G. Nelson, "Verification of rutting predictions from mechanistic-empirical pavement design guide by use of accelerated loading facility data," Transportation Research Record: Journal of the Transportation Research Board, vol. 2057, no. 1, pp. 157-167, 2008.

[15] Ministry of Communications of the People's Republic of China, Technical Specification for Construction of Highway Asphalt Pavements: JTG F40-2004, China Communications Press, Beijing, China, 2004.

[16] Ministry of Communications of the People's Republic of China, Field Test Methods of Subgrade and Pavement for Highway Engineering: JTG E60-2008, China Communications Press, Beijing, China, 2008.

[17] Z. Zhao, Z. Zhang, and C. Hu, "Influence of gradation on antiskidding performance of asphalt pavement," Journal of Chang'an University: Natural Science Edition, vol. 25, pp. 6-9, 2005, in Chinese.

[18] W. Tan and W.-A. Xuan, "Attenuation regularity of skid resistance of asphalt mixture," Journal of Chongqing Jiaotong University: Natural Science Edition, vol. 34, pp. 53-57, 2015, in Chinese.

[19] D. Chen, S. Han, C. Ling, and Q. Su, "Prediction of asphalt mixture surface texture level and its distributions using mixture design parameters," International Journal of Pavement Engineering, vol. 20, no. 5, pp. 557-565, 2019.

[20] J. Liu and G. Wang, "Study of asphalt pavement skid resistance attenuation characteristic," Aging and Application of Synthetic Materials, vol. 46, pp. 73-79, 2017. 